\title{
Correlation of patterns of denitrification instability in replicated bioreactor communities with shifts in the relative abundance and the denitrification patterns of specific populations
}

\author{
Margaret Elizabeth Gentile, Jennifer Lynn Nyman ${ }^{1}$ and Craig S Criddle \\ Department of Civil and Environmental Engineering, Stanford University, Stanford, CA, USA
}

\begin{abstract}
To assess the effects of community structure on the stability of denitrification, six chemostat cultures derived from the same denitrifying community were subjected to step increases in feed nitrate concentration and monitored for evidence that denitrification was either not occurring (indicated by the presence of nitrate) or was incomplete (indicated by the presence of nitrite or nitrous oxide). Functional stability was defined and quantified from the pattern of effluent concentration trends of nitrate and denitrification intermediates. Microbial community structure and dynamics were analyzed by terminal restriction fragment length polymorphism analysis of the 16S rRNA gene. Functional stability varied: one chemostat community lost the ability to reduce all of the influent nitrate; others continued to reduce all of the influent nitrate, but accumulated varying amounts of nitrous oxide. The microbial community structure in two of the chemostats diverged from the others, and variation of functional response among chemostats corresponded with the divergence of community structure. The Acidovorax-like terminal restriction fragment (T-RF) dominated the chemostat that accumulated nitrate, and an Acidovorax-like isolate reduced nitrate directly to dinitrogen gas in batch nitrate reduction assays. In the nitrous oxide-accumulating chemostats, the relative abundance of the Pseudomonas-like T-RF was strongly and significantly correlated with the magnitude of nitrous oxide accumulation, and a Pseudomonas-like isolate accumulated nitrous oxide in batch assays.
\end{abstract}

The ISME Journal (2007) 1, 714-728; doi:10.1038/ismej.2007.87; published online 18 October 2007

Subject Category: microbial engineering

Keywords: denitrification; environmental biotechnology; microbial community structure; replication; functional stability; microbial ecology

\section{Introduction}

Functional stability is a requirement of microbial communities in engineered water treatment systems, but the causes of instability are poorly understood. The elucidation of basic relationships between microbial community structure, dynamics (that is, changes in community structure) and functional stability is a key step toward the rational design of functionally stable systems (Briones and Raskin, 2003; Curtis et al., 2003; Rittmann et al., 2006).

Correspondence: ME Gentile, ARCADIS US Inc., 155 Montgomery St, Suite 1510, San Francisco, CA 94104, USA.

E-mail: Margaret.Gentile@arcadis-us.com

${ }^{1}$ Current address: Malcolm Pirnie Inc., Emeryville, CA, USA

Received 19 June 2007; revised 17 September 2007; accepted 18 September 2007; published online 18 October 2007
Previous studies examined changes in microbial community structure in response to perturbation in engineered systems. In two studies of methanogenic systems, dynamic microbial community responses to perturbation were observed (Fernandez et al., 2000; Sundh et al., 2003). In one of these studies, functional stability varied with community structure, and the systems with more dynamic communities had greater functional stability (Fernandez et al., 2000; Hashsham et al., 2000). Further experimentation in different microbial systems is needed to evaluate whether such correlations are general or system-specific.

Predictability and reliability are essential for the design and implementation of engineered systems. However, few studies of bioreactor community structure and function have examined replicated systems. In the few systems studied to date, the degree of reproducibility varied. For example, in 
five packed bed-denitrifying reactors, community structure replicated (McGuinness et al., 2006), but in a study of two sets of well-mixed methanogenic reactors, one in four replicates exhibited anomalous behavior (Hashsham et al., 2000). Many factors may potentially influence predictability and reliability, including reactor design (that is, scale, solids retention time, fixed film versus dispersed growth, and so on) and functional process (that is, nitrification, denitrification, methanogenesis, and so on). In order to evaluate the generality of ecological principles and the factors that control replicability and predictability, additional replicated experiments are needed.

Denitrification is a critical process in many engineering applications including nitrogen removal from wastewater and bioremediation of polluted groundwater, and it is also an important process in the global nitrogen cycle. In engineering denitrification applications, the system function of denitrification is defined as the complete reduction of nitrate to dinitrogen gas without the accumulation of intermediate products. Nitrite is a particularly problematic intermediate, because it is more toxic than nitrate, has a lower maximum contaminant level than nitrate (US Government Printing Office, 2002), threatens functional stability by inhibiting microbial growth and activity (Almeida et al., 1995; Glass et al., 1997; Glass and Silverstein, 1998), exerts oxygen demand, and poses an eutrophication threat to nutrient limited environments.

From an ecological perspective, denitrifying communities are particularly interesting for functional stability studies, due to their diversity. Denitrifiers can couple nitrate reduction to a diverse set of electron donors, allowing for the study of complex interactions, such as cross-feeding, that are not possible for other model ecological communities which are limited in their range of electron donor/ acceptor combinations, for example, ammonia oxidizing communities. Denitrifying species are also diverse in their tendencies to accumulate denitrification intermediates, especially nitrite and nitrous oxide (Betlach and Tiedje, 1981; Carlson and Ingraham, 1983; Martienssen and Schops, 1999). In addition, some members of denitrifying communities do not possess the entire denitrification pathway and are not true denitrifiers. For example, nitrate respirers, which reduce nitrate only to nitrite, are found in engineered denitrifying systems (Martienssen and Schops, 1999; Drysdale et al., 2001; Gentile et al., 2007) and may potentially contribute to the overall conversion of nitrate to nitrogen. Accordingly, this manuscript focuses on denitrification as a system function and considers the microbial community of interest to include all populations that contribute to the overall conversion of nitrate to nitrogen gas, including denitrifiers and nitrate respirers.

In this study, denitrification stability and its relationship to community structure were assessed by perturbing six replicate chemostat-grown denitrifying communities. Culture from a pilot-scale fluidized bed reactor (FBR) (Gentile et al., 2006) served as the inoculum. Culture from the same FBR was used to inoculate a field-scale FBR that treated nitrate and uranium contaminated water at the Department of Energy Environmental Remediation Sciences Program (ERSP, formerly the Natural and Accelerate Bioremediation Program) Field Research Center (FRC) in Oak Ridge, Tennessee (Hwang et al., 2005). For the work described in this manuscript, denitrifying chemostat cultures derived from the pilot-scale FBR were perturbed by transient step increases in feed nitrate concentration. Denitrification stability was assessed by perturbing the system and then monitoring effluent concentrations of nitrate, nitrite and nitrous oxide. Stability metrics were then calculated from the 'amplification envelopes' of these solutes using a method similar to that of Hashsham et al. (2000). In this case, the amplification envelopes were used to quantify the accumulation of the electron acceptor, nitrate, and intermediates along the reduction pathway of the electron acceptor, rather than the accumulation of the electron donor and intermediates along the oxidation pathway of the electron donor as in the Hashsham et al. (2000) study. Microbial community structure and dynamics were examined by terminal restriction length polymorphism (T-RFLP) analysis of the 16S rRNA gene. The microbial community structure in two of the chemostats diverged from the others. This divergence corresponded to changes in the extent of denitrification: nitrous oxide accumulated in chemostats containing an abundance of a population that, in pure culture, reduced nitrate to nitrous oxide, whereas nitrate accumulated in chemostats containing an abundance of a population that, in pure culture, reduced nitrate to dinitrogen gas without accumulation of intermediates.

\section{Materials and methods}

\section{Chemostat specifications}

Six identical chemostats, designated R1 through R6, were constructed from 150-ml tubular glass vessels, and a schematic of chemostat construction is presented in Supplementary Figure S1. To minimize biofilm formation on vessel walls, the vessels were silanized. To ensure anoxic conditions, sterile rubber stoppers were fitted to the tops of each vessel and installed with glass tubing ports for feed, waste and pressure venting. Samples were taken with sterile syringes from the side of the chemostats via blown glass sampling ports fitted with rubber septa. Each chemostat contained a magnetic stir bar and was individually mixed on one position of a multiposition stir plate (IKA, Wilmington, NC, USA). All six chemostats were fed and wasted by a 12-channel peristaltic pump consisting of a 
Masterflex 7523-70 console drive (Cole-Parmer, Barrington, IL, USA) and 12-channel Masterflex 7519-25 pump head (Cole-Parmer) fitted with Masterflex 7519-85 cartridges (Cole-Parmer). Effluent pump rates were set approximately $13 \%$ higher than influent pump rates, and the open end of a piece of glass tubing used to remove culture from the chemostat was positioned such that the volume of chemostat was maintained at $60 \mathrm{ml}$.

During the first perturbation, the dilution rates varied by $5 \%$ among chemostats with an average rate of $0.041 \pm 0.002 \mathrm{~h}^{-1}$, as calculated from bromide tracer breakthrough curves. The dilution rate was higher during the third perturbation with an average of $0.048 \pm 0.002 \mathrm{~h}^{-1}$, and the increase was likely due to an increase in flow rates due to some wearing of the feed tubing. The increase in dilution rate from the first perturbation to the third was greater than the variation of dilution rates among the chemostats for a given perturbation.

The amount of gas in the headspace continually declined in the vessels, due to the difference in influent and effluent pump rates. Vent lines fitted with sterile $0.45 \mu \mathrm{M}$ syringe filters and balloons were used to maintain ambient headspace pressure as gas was removed. Headspace was replenished with anaerobic dinitrogen gas through the sterile rubber stopper with a sterile syringe and $0.45 \mu \mathrm{M}$ syringe filter as needed.

The original source of organisms was a denitrifying culture enriched from groundwater from well TPB-16 at the ERSP Oak Ridge FRC. Inoculum from this enrichment culture was subsequently used to inoculate a pilot-scale FBR (Gentile et al., 2006), a set of 21 dispersed growth reactors (Gentile et al., 2007) and a field-scale FBR at the FRC (Hwang et al., 2005). Culture from one of the 21 dispersed growth reactors, described elsewhere (Gentile et al., 2007), was split and used to inoculate each of the six chemostats. The $2 \mathrm{l}$ reactor used for chemostat inoculation was operated for 16 months under the same feed conditions as the chemostats prior to their inoculation. On day zero of the present study, autoclaved reactor vessels were filled with sterile, oxygen-free dinitrogen gas and each received $60 \mathrm{ml}$ of inoculum. The feed pump and effluent pump were then started.

\section{Media composition}

All six chemostats were fed from a single, sterile feed carboy. The feed solution consisted of nitrate, lactic acid and ethanol as electron donors, nutrient salts and trace elements. Concentrations varied during unperturbed (baseline) and perturbed periods. For baseline conditions, the feed solution contained the following electron acceptors and electron donors: $0.64 \mathrm{gl}^{-1} \mathrm{NaNO}_{3}, 0.76 \mathrm{gl}^{-1} \mathrm{KNO}_{3}$, $0.44 \mathrm{~g} \mathrm{l}^{-1} \mathrm{C}_{2} \mathrm{H}_{6} \mathrm{O}$, and $1.02 \mathrm{~g} \mathrm{C}_{3} \mathrm{H}_{6} \mathrm{O}_{3}$. This composition of media resulted in a chemical oxygen demand to nitrogen $(\mathrm{COD} / \mathrm{N})$ ratio of $8.2 \mathrm{~g} \mathrm{COD} / \mathrm{N}$, twice the requirement of $4.4 \mathrm{~g}$ COD/N predicted for the implemented dilution rate based on typical stoichiometric and kinetic parameters for denitrification (Rittmann and McCarty, 2001). The supply of elevated concentrations of electron donors was required to achieve complete denitrification during the start-up of the dispersed growth reactors used to inoculate the chemostats (Gentile et al., 2007) and during start-up in several trial runs of chemostat operation (data not shown). The high electron donor requirement indicated the presence of an electron sink within the system in addition to denitrification. The baseline feed solution also contained the following nutrient salts: $14 \mathrm{mg} \mathrm{l}^{-1} \mathrm{Na}_{3} \mathrm{P}_{3} \mathrm{O}_{9}, 7 \mathrm{mg} \mathrm{l}^{-1}$ $\mathrm{NaSO}_{4}, \quad 11 \mathrm{mg} \mathrm{l}^{-1} \quad \mathrm{MgCl}_{2} \cdot 6 \mathrm{H}_{2} \mathrm{O}$, and $15 \mathrm{mg} \mathrm{l}^{-1}$ $\mathrm{CaCl}_{2} \cdot 2 \mathrm{H}_{2} \mathrm{O}$. Trace elements were provided in the following concentrations: $0.3 \mathrm{mgl}^{-1} \mathrm{FeCl}_{2} \cdot 4 \mathrm{H}_{2} \mathrm{O}$, $0.1 \mathrm{mgl}^{-1} \quad \mathrm{ZnSO}_{4} \cdot 7 \mathrm{H}_{2} \mathrm{O}, \quad 85 \mu \mathrm{gl}^{-1} \quad \mathrm{MnSO}_{4} \cdot \mathrm{H}_{2} \mathrm{O}$, $60 \mu \mathrm{gl}^{-1} \mathrm{H}_{3} \mathrm{BO}_{3}, 19 \mu \mathrm{gl}^{-1} \mathrm{CoCl}_{2} \cdot 6 \mathrm{H}_{2} \mathrm{O}, 4 \mu \mathrm{gl}^{-1} \mathrm{Cu}-$ $\mathrm{SO}_{4} \cdot 5 \mathrm{H}_{2} \mathrm{O}, 28 \mu \mathrm{gl}^{-1} \mathrm{NiSO}_{4} \cdot 6 \mathrm{H}_{2} \mathrm{O}$ and $40 \mu \mathrm{gl}^{-1} \mathrm{Na}_{2-}$ $\mathrm{MoO}_{4} \cdot 2 \mathrm{H}_{2} \mathrm{O}$. The $\mathrm{pH}$ of the feed solution was adjusted with $2 \mathrm{~N} \mathrm{NaOH}$ to a range of 3.0-4.0, depending upon influent nitrate and lactic acid concentrations. The production of alkalinity during denitrification neutralized the remaining acidity and resulted in $\mathrm{pH}$ between approximately 7.5 and 8.0.

\section{Perturbation experiments}

The perturbations were designed to test two common operational scenarios in engineered systems: (1) the case in which the influent concentration of nitrate increases, and the system control responds by increasing the electron donor concentration so as to maintain nitrogen removal, and (2) the case in which the influent nitrate concentration increases, but system control fails to respond.

After inoculation, all six chemostats were operated under the same baseline conditions with a feed nitrate concentration of $15 \mathrm{mM} \mathrm{NO}_{3}^{-}-\mathrm{N}$ for 42 days. The chemostats were then subjected to a series of three perturbations in which feed nitrate concentrations were instantaneously increased by $60 \%$ to $24 \mathrm{mM} \mathrm{NO}-\mathrm{N}$ for a period of $67 \mathrm{~h}$. For all three perturbations, the concentrations of nutrient salts were increased in proportion to the increase in nitrate concentration, while trace element concentrations were maintained at the level of the baseline feed solution. The first perturbation began on day 42 and ended on day 45. The first scenario described above was tested in this perturbation: the concentrations of lactic acid and ethanol in the feed were increased in proportion to the increase in the concentration of nitrate, and the feed COD/N ratio did not change. The second and third perturbations were instituted from days 56 to 59 and days 112 to 115, respectively. In each of these perturbations the second scenario described above was tested: the concentrations of lactic acid and ethanol were maintained at a constant concentration while nitrate 
concentration increased, resulting in a lower feed $\mathrm{COD} / \mathrm{N}$ ratio of 5.0 .

Samples for chemical and microbial community analyses were taken every 2-3 days during unperturbed operation, every $6 \mathrm{~h}$ during the perturbation, and every $6 \mathrm{~h}$ for several days following the perturbation. Liquid samples for nitrate, nitrite, ethanol, lactate and volatile fatty acid analyses were removed from each chemostat, centrifuged at $16000 \mathrm{~g}$ for $10 \mathrm{~min}$, decanted and stored at $-20^{\circ} \mathrm{C}$. Liquid samples for nitrous oxide quantification were removed from chemostats and injected into $10 \mathrm{ml}$ sealed serum vials filled with anaerobic helium. Samples of gas from the headspace of the serum vials were removed with a gas-tight Hamilton syringe and analyzed immediately. Liquid concentrations of nitrous oxide were then calculated using a Henry's constant of $2.4 \times 10^{-2} \mathrm{~mol} \mathrm{l}^{-1} \mathrm{~atm}^{-1}$ (Wilhelm et al., 1977). Total production of nitrous oxide was underestimated by liquid concentration, because an estimated $19 \%$ was removed with the gas phase effluent. Samples for microbial community analysis were removed from chemostat sampling ports with sterile syringes, centrifuged for $2 \mathrm{~min}$ at $16000 \mathrm{~g}$, decanted, and stored at $-20^{\circ} \mathrm{C}$ until analysis. To archive cell pellets for protein analysis, $0.25 \mathrm{ml}$ aliquots of sample were transferred into a sterile centrifuge tubes, centrifuged at $16000 \mathrm{~g}$ for $10 \mathrm{~min}$, decanted and stored at $-20^{\circ} \mathrm{C}$ until analysis.

\section{Microbial community analysis}

The 16SrRNA gene was targeted for molecular microbial community analysis in this study rather than the widely used denitrification functional genes nirS, nirK and nosZ in order to include nitrate respiring organisms that do not possess nitrate reductase or nitrous oxide reductase. Nitrate respiring organisms were considered potentially important, based on the findings of previous work with the microbial community used in this study (Gentile et al., 2007).

DNA extraction and purification. DNA from all samples was extracted using an Ultraclean Microbial DNA Kit according to manufacturer's instructions (MoBio Laboratories, Carlsbad, CA, USA).

PCR amplification and purification. 16S rRNA genes were amplified with a GeneAmp PCR System 9700 Thermocycler (Applied Biosystems, Pleasanton, CA, USA) from community genomic DNA using primer pair $8 \mathrm{~F}$ (5'AGAGTTTGATCCTGGCTCAG3') fluorescently labeled with hexachlorofluorescein and unlabeled 1392R (5'ACGGGCGGTGTGTRC3') (Lane, 1991) (Qiagen Operon, Alameda, CA, USA). PCR reactions $(50 \mu \mathrm{l})$ contained $1 \times$ PCR buffer (100 mM KCl, $20 \mathrm{~mm}$ Tris HCl pH 8.0, $0.1 \mathrm{~mm}$ EDTA, $1 \mathrm{mM}$ DTT, $50 \%$ glycerol, $0.5 \%$ Tween and $0.5 \%$ Nonidet-P40; supplied with the Taq polymerase by Promega, Madison, WI, USA), $2.5 \mathrm{mM} \mathrm{MgCl}_{2}, 5 \%$ dimethylsulfoxide, $0.4 \mathrm{~mm}$ each dNTP (Invitrogen, Carlsbad, CA, USA), 12.5 pmol each primer, $1.5 \mathrm{U}$ of Taq DNA polymerase in storage buffer B (Promega), and $40 \mathrm{ng}$ of template DNA. Samples were placed into a thermocycler preheated to $94^{\circ} \mathrm{C}$. The PCR thermal cycling parameters were as follows: $94{ }^{\circ} \mathrm{C}$ for $45 \mathrm{~s}, 55^{\circ} \mathrm{C}$ for $30 \mathrm{~s}, 72{ }^{\circ} \mathrm{C}$ for $1.5 \mathrm{~min}, 30$ cycles; $72{ }^{\circ} \mathrm{C}$ for $7 \mathrm{~min}$. PCR products were analyzed on $1.8 \%(\mathrm{w} / \mathrm{v})$ TBE agarose gels, and the product size was confirmed. Products for three replicate PCR reactions were combined for each sample and purified with the Montage PCR Centrifugal Device (Millipore, Billerica, MA, USA).

\section{Terminal restriction length polymorphism}

(T-RFLP). Restriction digests for T-RFLP contained $10 \mathrm{ng} \mu \mathrm{l}^{-1}$ of purified PCR product and $1 \mathrm{U}_{\mu \mathrm{l}^{-1} \text { of }}$ enzyme in buffer provided by the manufacturer. The samples were digested with HaeIII (Invitrogen) at $37^{\circ} \mathrm{C}$ for $3 \mathrm{~h}$, and then the enzyme was deactivated in a $65{ }^{\circ} \mathrm{C}$ water bath for $10 \mathrm{~min}$. Digests with enzyme TaiI (Fermentas Life Sciences, Hanover, MD, USA) were carried out at $65^{\circ} \mathrm{C}$ for $3 \mathrm{~h}$. All digests were desalted by purification with the Montage PCR Centrifugal Device (Millipore). Restriction digest products were analyzed on an ABI PRISM 3100 Genetic Analyzer at the Genomics Technology Support Facility, Michigan State University.

T-RFLP profiles were standardized based on previously developed methods (Dunbar et al., 2000; Kaplan et al., 2001). Total signal was calculated as the sum of peak heights. Profiles were standardized to the sample with the lowest total signal and peaks with adjusted heights lower than the threshold (50 fluorescent units) were removed. The relative abundance of each terminal restriction fragment (T-RF) was calculated as the ratio of peak height for that T-RF to the sum of peak heights for all T-RFs in the profile and expressed as a percentage. Histograms were prepared from relative abundance data.

Quantitative community comparisons. The similarity between communities was measured using the Bray-Curtis coefficient, also known as the Steinhaus index (Legendre and Legendre, 1998). The software package PAST (Hammer et al., 2001) was used to calculate matrices of pairwise Bray-Curtis similarities. Cluster analysis using the unweighted pair-group average (UPGMA) algorithm and the Bray-Curtis index was also preformed in PAST.

\section{Isolations and nitrate reduction assays}

Several organisms representative of chemostat community members were isolated from communities that were predecessors of the chemostats examined in this study (Gentile et al., 2006, 2007). Phylogenetic analysis of isolates M2, D3, D6 and G1 is described elsewhere (Gentile et al., 2007). The 
nitrate reduction assays of isolates M2, D6 and G1 are also described elsewhere (Gentile et al., 2007). Isolate D3 was assayed for reduction of nitrate and production of nitrite, nitrous oxide and dinitrogen gas. Batch assays were carried out in sealed anaerobic serum bottles with a helium headspace and the following media composition: $210 \mathrm{mg} \mathrm{l}^{-1}$ $\mathrm{NaNO}_{3}, 139 \mathrm{mg} \mathrm{l}^{-1} \mathrm{NaC}_{3} \mathrm{H}_{5} \mathrm{O}_{3}$ or $57 \mathrm{mg} \mathrm{l}^{-1} \mathrm{C}_{2} \mathrm{H}_{6} \mathrm{O}$, $2.6 \mathrm{~g} \mathrm{l}^{-1} \mathrm{NaHCO}_{3}$ and other nutrients in the same proportions as in the feed solutions for the chemostats. Isolate D3 was grown aerobically in LB media, centrifuged at $5000 \mathrm{~g}$ for $20 \mathrm{~min}$, and washed three times before inoculation. Each wash step consisted of removal of the supernatant, suspension of the cell pellet in bicarbonate buffer $\left(2.6 \mathrm{~g} \mathrm{l}^{-1} \mathrm{NaHCO}_{3}\right)$, and centrifugation at $5000 \mathrm{~g}$ for $15 \mathrm{~min}$. Liquid samples were periodically removed from serum bottles, centrifuged at $16000 \mathrm{~g}$ for $10 \mathrm{~min}$, decanted and stored at $-20^{\circ} \mathrm{C}$ for nitrate and nitrite analysis. Gas samples were removed with Hamilton syringes and analyzed immediately.

\section{Analytical methods}

Nitrate and nitrite were measured using an ion chromatograph, with a detection limit of $25 \mu \mathrm{M}$ for both compounds (Dionex, Sunnyvale, CA, USA). Ion chromatography was also used to measure lactate concentrations and to detect and measure the formation of volatile fatty acids including acetate, propionate, butyrate and formate. Nitrous oxide was measured on an HP5890 gas chromatograph (Hewlett Packard, Palo Alto, CA, USA) equipped with a CARBONPLT column and an electron capture detector (Agilent Technologies, Palo Alto, CA, USA). Nitrogen production in batch assays of isolates was quantified by a gas chromatograph with a thermal conductivity detector (Gow-Mac Instrument Company, Lehigh, PA, USA). Ethanol was measured in $0.03 \mathrm{M}$ oxalic acid by direct liquid injection on a HP5890 gas chromatograph (Hewlett Packard) equipped with a packed column (80/120 Carbopack B-DB/4\% Carbowax 20 M column) and flame ionization detector.

Protein from whole cells served as a surrogate for biomass concentration. Cell pellets were resuspended in $0.3 \mathrm{ml}$ of B-Per bacterial protein extraction reagent (Pierce, Rockford, IL, USA), vortexed for $1 \mathrm{~min}$, and centrifuged at $16000 \mathrm{~g}$ for $10 \mathrm{~min}$ Protein concentrations in the supernatant were assayed with Micro BCA Protein Assay Regent Kit (Pierce) according to manufacturer's instructions. Volatile suspended solids (VSS) concentration of the inoculum was measured in duplicate, and protein concentration of the inoculum was measured in triplicate. The ratio of volatile suspended protein to solids in the inoculum was $0.60 \mathrm{~g}$ protein per gram VSS, and this factor was subsequently used to convert protein concentrations to VSS concentrations. VSS concentrations were measured according to Standard Method 2540E (Eaton et al., 1995).

\section{Results}

\section{Functional performance}

On day zero, six identical chemostats, designated R1 through R6, were inoculated with a denitrifying culture that had been maintained in the lab for 16 months prior in a 21 dispersed growth reactor, described elsewhere (Gentile et al., 2007). Chemostats were operated for a total of 130 days. After a 42-day start-up period in which the feed contained $15 \mathrm{mM} \mathrm{NO}_{3}^{-}-\mathrm{N}$, a series of three perturbations consisting of step increases in feed concentrations to $24 \mathrm{mM} \mathrm{NO}_{3}^{-}-\mathrm{N}$ were instituted.

Start-up, days 0-42. Chemostats were inoculated by transfer of $60 \mathrm{ml}$ of denitrifying enrichment culture into each chemostat. After 14 days of operation, nitrate was completely reduced (Figure 1) with no accumulation of nitrite (data not shown) or nitrous oxide, except in $\mathrm{R} 2$ where the effluent concentrations increased to $2 \mathrm{mM} \mathrm{N}_{2} \mathrm{O}-\mathrm{N}$ from days 38 to 42 .

The concentrations of ethanol and lactate, the electron donors, varied over time and among chemostats for several weeks after start-up (Supplementary Figures S2a and S3a). Despite the supply of excess COD as ethanol and lactate (see Materials and methods), effluent COD concentrations declined to less than $100 \mathrm{mg} \mathrm{l}^{-1}$ of each by day 38, corresponding to greater than $90 \%$ consumption. In addition to lactate and ethanol, acetate was also detected in the effluent at concentrations of up to $316 \mathrm{mg}$ COD per liter (Supplementary Figure S4a), indicating that a portion of the ethanol or lactate was possibly converted through fermentation to acetate.

Protein concentrations were measured and converted to biomass concentrations in units of VSS per unit of liquid volume using an experimentally derived conversion factor (see Materials and methods). There was considerable variation in biomass concentration within and between chemostats during the first 42 days of constant operation (Supplementary Figure S5a). Average chemostat concentrations varied by $11 \%$ and ranged from 132 to $173 \mathrm{mg}$ VSS per liter. $\mathrm{pH}$ values varied between 7.7 and 8.2 (Supplementary Figure S6a).

First perturbation-increase in electron donor concentrations. From days 42 to 45 , all six chemostats were perturbed by a $60 \%$ step increase in feed nitrate concentration to $24 \mathrm{mM} \quad \mathrm{NO}_{3}^{-}-\mathrm{N}$ with a proportional increase in electron donor. No loss of function occurred. Nitrate (Figure 1a) and nitrite (data not shown) were not detected, and nitrous oxide was only detected in R2 (Figure 1b). The nitrous oxide produced in R2 prior to this perturbation declined, suggesting that conditions during the perturbation favored complete reduction. During baseline conditions between the first and second perturbations, the concentration of nitrous oxide rebounded in $\mathrm{R} 2$, reaching concentrations above 

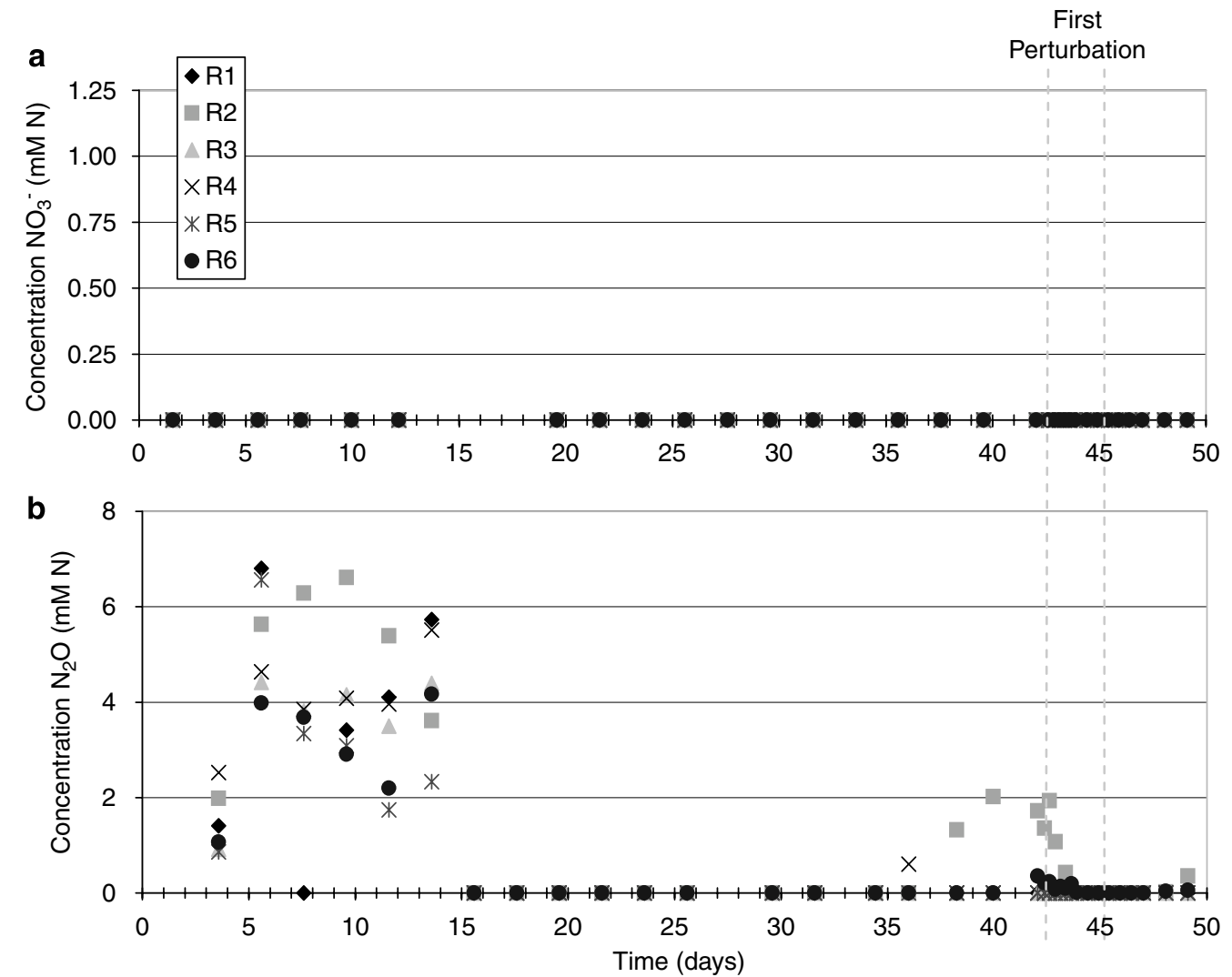

Figure 1 Functional performance for the first 50 days, including the chemostat start-up and the first perturbation in which nitrate concentrations were increased with a proportional increase in electron donor concentrations. (a) Effluent nitrate concentrations and (b) effluent nitrous oxide concentrations.

4 mM N. Nitrous oxide concentrations in R5 and R6 also increased slightly prior to the second perturbation.

In general, the concentrations of lactate, ethanol and acetate increased during the first perturbation and declined following the first perturbation, although the maximum concentrations varied among the chemostats (Supplementary Figures S2a, S3a, and S4a). In addition, propionate increased in chemostats R1, R2 and R4, suggesting lactate fermentation to acetate and propionate, a characteristic activity of propionic acid bacteria (Supplementary Figure S7a). In batch assays conducted in anaerobic media containing lactate without an electron acceptor, lactate was fermented stoichiometrically to acetate and propionate by the microbial community used to inoculate the chemostats (data not shown), suggesting the potential presence of propionic acid bacteria. The increase in organic acids in response to the first perturbation along with the decrease in nitrous oxide production in R2 suggests that there was a greater electron donor excess during this perturbation than during baseline conditions. The greater excess may have occurred because the propionic acid bacteria did not grow fast enough to degrade the increased electron donor concentration and thus were not able to consume the same proportion of the electron donor as they did when acclimated to the baseline feed conditions.

Biomass concentrations increased during the perturbation with the magnitude of the increase ranging from $37 \mathrm{mg}$ VSS per liter (R6) to $206 \mathrm{mg}$ VSS per liter (R1) (Supplementary Figure S5a). pH values declined during the perturbation, ranging from 7.1 to 7.5 , and returned to range from 7.8 to 8.0 following the perturbation (Supplementary Figure S6a).

Second and third perturbations: no increase in electron donor concentrations. The second and third perturbations were carried out on days 56 through 59 and on days 112 through 115, respectively. In both of these perturbations, the electron donor concentration in the feed was held constant while the feed nitrate concentration was increased, resulting in a decrease in the electron donor to electron acceptor $(\mathrm{COD} / \mathrm{N})$ ratio. During these perturbations, effluent concentrations of lactate, acetate and propionate generally declined (Supplementary Figures S2b, S2c, S4b, S4c, S7b and S7c), while ethanol concentrations varied sporadically during and in between perturbations (Supplementary Figures S3b and S3c). $\mathrm{pH}$ values increased slightly during the second perturbation (Supplementary Figure S6b), but remained relatively 
constant during the third perturbation (Supplementary Figure S6c).

All chemostats lost the capability to completely reduce nitrate during the second and third perturba- tions, but the nature of the compound that accumulated in the effluent-that is, whether nitrate or nitrous oxide-varied among chemostats (Figures 2 and 3). Two distinct patterns resulted: (1) loss of

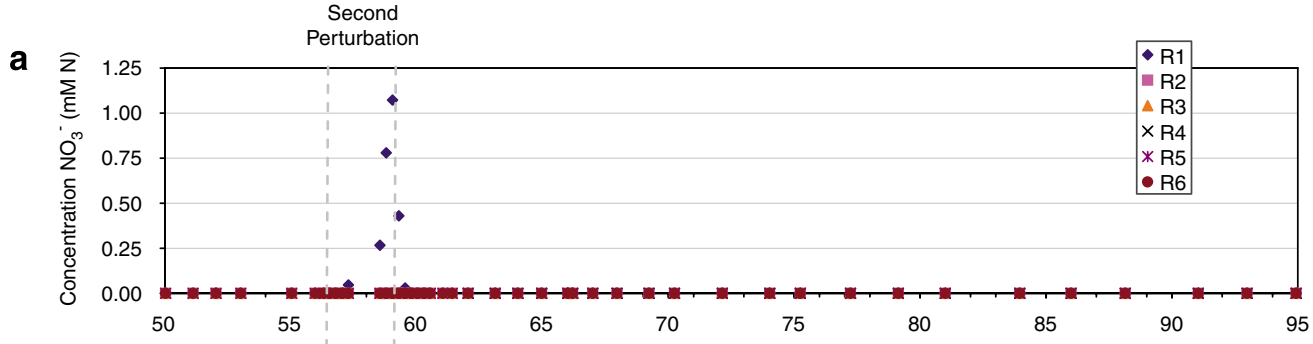

b

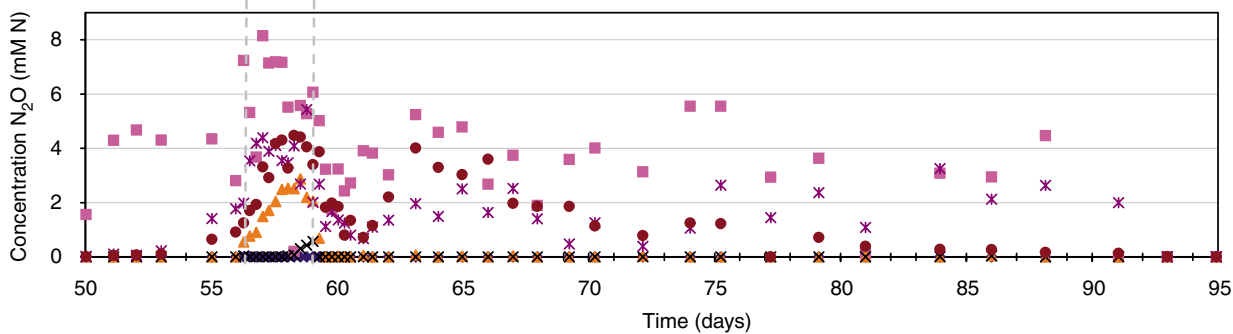

Figure 2 Functional performance from day 50 to day 95, including the second perturbation in which nitrate concentrations were increased and electron donor concentrations remained constant. (a) Effluent nitrate concentrations and (b) effluent nitrous oxide concentrations.

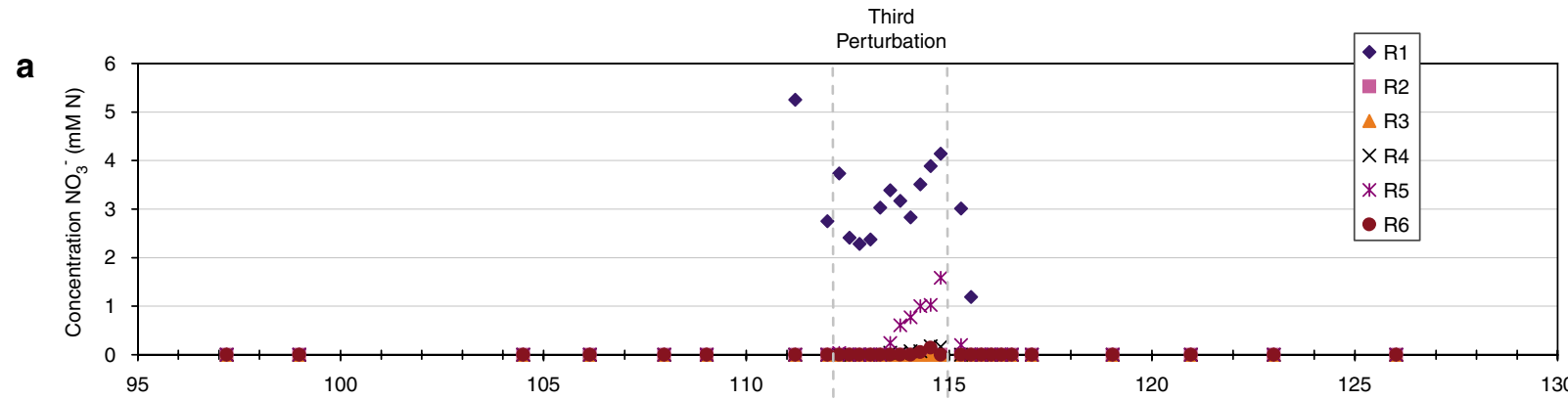

b

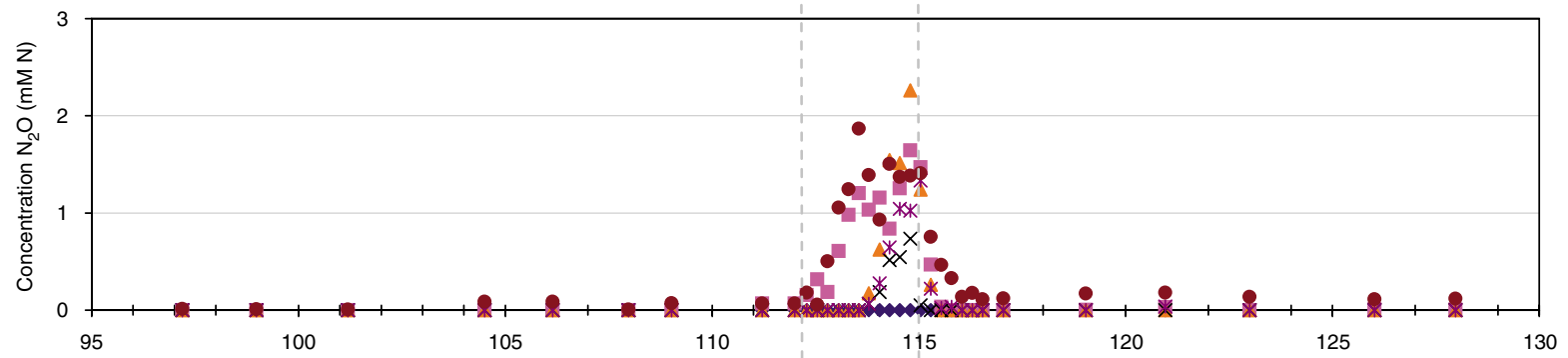

C

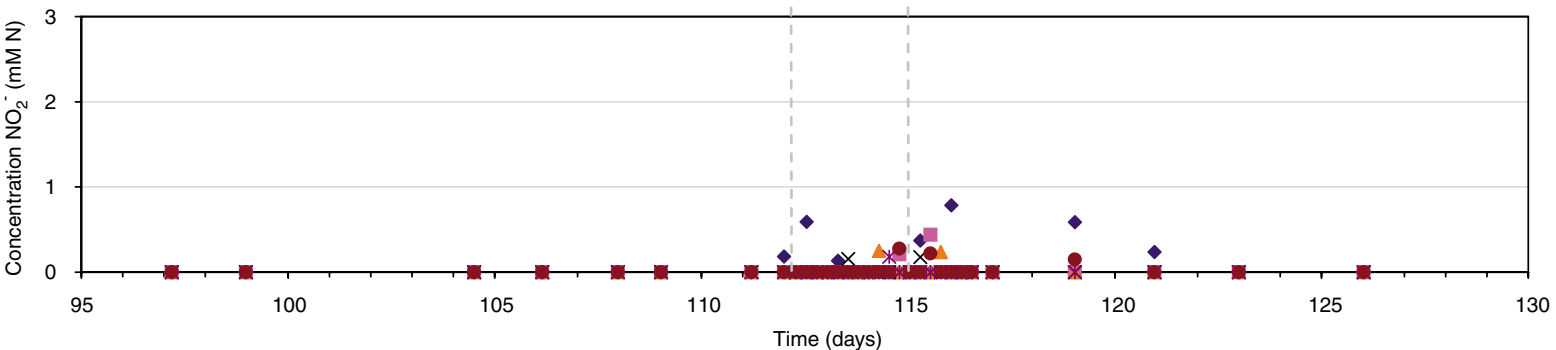

Figure 3 Functional performance from day 95 to day 130, including the third perturbation in which nitrate concentrations were increased and electron donor concentrations remained constant. (a) Effluent nitrate concentrations, (b) effluent nitrous oxide concentrations and (c) effluent nitrite concentrations. 
nitrate reduction in the effluent of $\mathrm{R} 1$ in both perturbations and of R5 in the third perturbation (Figures 2a and 3a), and (2) accumulation of nitrous oxide in the effluent in R2-R6 (Figures $2 b$ and $3 b$ ). Nitrite was not detected in the second perturbation, but appeared sporadically and at low levels in several chemostats during the third perturbation (Figure 3c). Despite the appearance of high concentrations of nitrate and nitrous oxide in chemostat effluents during the second and third perturbations, denitrification continued howbeit at a lower rate. The sum of concentrations nitrate, nitrite and nitrous oxide as nitrogen in chemostat effluents never equaled the concentration of nitrate as nitrogen in the influent. Greater than approximately $65 \%$ of influent nitrate was converted to nitrogen in all six chemostats throughout the 130 days of operation.

The majority of chemostats, R2-R6, continued to reduce the entire influent nitrate, and responded to the second and third perturbations with accumulation of nitrous oxide (Figures $2 \mathrm{~b}$ and $3 \mathrm{~b}$ ). During baseline conditions prior to the second perturbation, R2, R5 and R6 produced a nitrous oxide residual. R2, R3, R5 and R6 all responded to the step increase in feed nitrate during the second perturbation with rapid increases in nitrous oxide followed by a decline when nitrate loadings were restored to preperturbation levels. The pattern of nitrous oxide accumulation was most clear in R3 where complete removal of nitrous oxide occurred prior to and following the perturbation. Nitrous oxide concentrations in R2, R5 and R6 varied and remained elevated for 2 months following the second perturbation.

Because the functional response to the second perturbation was somewhat obscured by the nitrous oxide production during baseline conditions in R2, R5 and R6 and to confirm the relationships between functional stability and community structure observed during the second perturbation (discussed below), a third perturbation, identical to the second, was conducted after all of the chemostats were reducing all of the influent nitrate without producing nitrous oxide under baseline conditions. The accumulation of nitrous oxide in response to the third perturbation was clear in chemostats R2 through R6 but the shape of the nitrous oxide amplification envelope varied: R2 and R6 produced nitrous oxide immediately after the perturbation, while R3, R4 and R5 exhibited a delayed response.

Interpretation of the effects of perturbation was obscured in two instances by clogging of the feed lines. This occurred in chemostat R1 on day 107 and in chemostat R4 on day 56 . The clogging in the R1 feed line led to an increase in nitrate concentration prior to the third perturbation, but the response was still observed, with nitrate levels increasing at the onset of the perturbation and rapidly declining at its end (Figure 3a). Similarly, clogging in the R4 feed lines at the very beginning of the second pertur- bation made it impossible to assess the functional response to this perturbation. These were the only two clogging events in all six chemostats for the 130 days of operation.

Quantitative analysis of nitrate and nitrous oxide concentration trends in response to the second and third perturbations. The amplification envelope is the concentration profile of denitrification intermediates (nitrite and nitrous oxide) as they accumulated and were subsequently removed in response to perturbation. The parameters resistance and stability previously adopted from ecology describe the amplification envelopes (Grimm et al., 1992; Hashsham et al., 2000) and were used in this study to quantify and compare the response to perturbation with respect to nitrate and nitrous oxide (Table 1). Resistance is a measure of a system's sensitivity to perturbation (Grimm et al., 1992) and was quantified for a given compound as the maximum concentration accumulated (Hashsham et al., 2000). A high numerical value thus corresponds to low resistance. Overall stability incorporates both resistance and resilience, the time to return to a referential state after perturbation, and was calculated as the area under the amplification envelope. As with resistance, a high numerical value indicates low stability. Because the electron donor feed lines for chemostat R1 and R4 clogged prior to the second and third perturbations, respectively, data for these chemostats were not included in the analysis.

Resistance and stability metrics revealed that the most stable system in the third perturbation was R4 (Table 1a). The magnitude of the nitrous oxide response in R4 was significantly lower than the averages for the other nitrous oxide-producing chemostats (R2, R3, R5 and R6) despite the high variability among these chemostats (Table 1b). The set of chemostats that accumulated high concentrations of nitrous oxide (R2, R3, R5 and R6) was more stable with respect to the third perturbation than to the second (Table 1b). Although chemostat R1 accumulated nitrate rather than nitrous oxide, the resistance and overall stability calculated for this chemostat for the second perturbation was not significantly different from the average resistance and overall stability of chemostats R2, R3, R5 and R6 for the second perturbation.

\section{Microbial community analysis}

To assess the variability of community structure among chemostats and over time, samples were archived throughout the experiment. From this archive, samples were selected and analyzed by TRFLP with the restriction enzyme HaeIII (Figure 4). In previous work, a clone library was constructed from the community used to inoculate the chemostats (Gentile et al., 2007) and isolates were functionally characterized. The $16 \mathrm{~S}$ rRNA 
Table 1 Resistance is reported as the maximum concentration accumulated

\begin{tabular}{|c|c|c|c|c|c|c|c|}
\hline \multirow[t]{2}{*}{ (a) } & & \multicolumn{3}{|c|}{ Resistance } & \multicolumn{3}{|c|}{ Total stability } \\
\hline & & $\begin{array}{c}\mathrm{NO}_{3}^{-} \text {(mmole e- equiv } \\
\text { per liter) }\end{array}$ & $\begin{array}{c}\mathrm{N}_{2} \mathrm{O} \text { (mmole } \\
\text { e- equiv per liter) }\end{array}$ & $\begin{array}{l}\mathrm{NO}_{3}^{-}+\mathrm{N}_{2} \mathrm{O} \text { (mmole } \\
\text { e- equiv per liter) }\end{array}$ & $\begin{array}{c}\mathrm{NO}_{3}^{-} \text {(mmole } \\
\text { e- equiv } \text { day per liter) }\end{array}$ & $\begin{array}{c}\mathrm{N}_{2} \mathrm{O} \text { (mmole } \\
\text { e- equiv } \text { day per liter) }\end{array}$ & $\begin{array}{c}\mathrm{NO}_{3}^{-}+\mathrm{N}_{2} \mathrm{O}(\text { mmole } \\
\text { e- equiv } \text { day per liter })\end{array}$ \\
\hline \multirow[t]{5}{*}{ Second perturbation } & R1 & 5.4 & 0.0 & 5.4 & 12.2 & 0.0 & 12.2 \\
\hline & R2 & 0.0 & $5.3^{\mathrm{a}}$ & 5.3 & 0.0 & $10.9^{\mathrm{a}}$ & 10.9 \\
\hline & R3 & 0.0 & 2.5 & 2.5 & 0.0 & 5.8 & 5.8 \\
\hline & R5 & 0.0 & $3.7^{\mathrm{a}}$ & 3.7 & 0.0 & $5.9^{\mathrm{a}}$ & 5.9 \\
\hline & R6 & 0.0 & $3.7^{\mathrm{a}}$ & 3.7 & 0.0 & $8.7^{\mathrm{a}}$ & 8.7 \\
\hline \multirow[t]{5}{*}{ Third perturbation } & $\mathrm{R} 2$ & 0.0 & 1.7 & 1.7 & 0.0 & 2.9 & 2.9 \\
\hline & R3 & 0.0 & 2.3 & 2.3 & 0.0 & 1.9 & 1.9 \\
\hline & R4 & 0.0 & 0.7 & 0.7 & 0.0 & 0.3 & 0.3 \\
\hline & R5 & 7.9 & 1.3 & 9.2 & 6.8 & 1.2 & 7.9 \\
\hline & R6 & 0.0 & 1.9 & 1.9 & 0.0 & 3.7 & 3.7 \\
\hline \multirow[t]{3}{*}{ (b) } & \multirow{2}{*}{\multicolumn{2}{|c|}{ Second perturbation }} & \multirow{2}{*}{\multicolumn{2}{|c|}{ Third perturbation }} & & & \\
\hline & & & & & & & \\
\hline & $\begin{array}{l}\text { Resistance (mmole } \\
\text { e-equiv per liter) }\end{array}$ & $\begin{array}{l}\text { Total stability (mmole } \\
\text { e- equiv } \text { day per liter) }\end{array}$ & $\begin{array}{l}\text { Resistance (mmole } \\
\text { e- equiv per liter) }\end{array}$ & $\begin{array}{l}\text { Total Stability (mmole } \\
\text { e-equiv } \text { day per liter) }\end{array}$ & & & \\
\hline $\begin{array}{l}\text { Average } \\
\text { c.v. }\end{array}$ & $\begin{array}{c}3.8 \pm 1.1 \\
30\end{array}$ & $\begin{array}{l}7.8 \pm 2.4 \\
31\end{array}$ & $\begin{array}{l}1.8 \pm 0.4 \\
22\end{array}$ & $\begin{array}{l}2.4 \pm 1.1 \\
46\end{array}$ & & & \\
\hline
\end{tabular}

Abbreviations: CI, confidence intervals; c.v., co-efficient of variation; equiv, equivalent; s.d., standard deviation.

Total stability was calculated as the area under the amplification envelope using the Trapezoidal Rule. Averages of R2, R3, R5 and R6 $+95 \%$ confidence intervals.

${ }^{2}$ Elevated levels of nitrous oxide were detected in chemostats R2, R5 and R6 prior to the second perturbation. The stability parameters for these cases were calculated considering the preperturbation level as a baseline. 

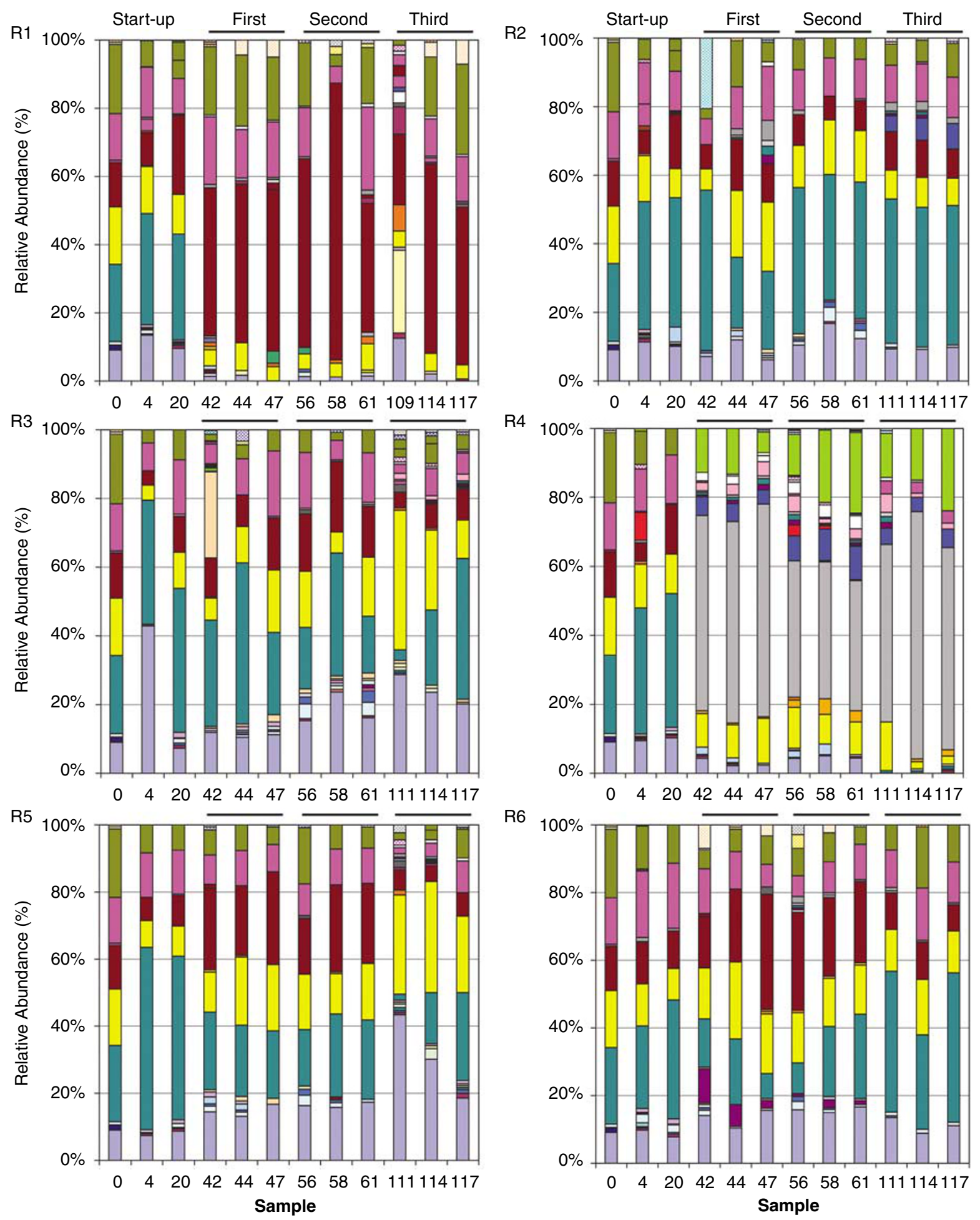

Primary Fragments

\begin{tabular}{|c|c|}
\hline $31 \mathrm{bp}$, Pseudomonas & 215 bp, Acidovorax \\
\hline 197 bp, Delftia & 217 bp, Achromobacter \\
\hline
\end{tabular}

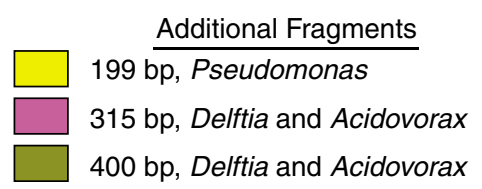

Figure 4 Histograms of T-RF relative abundances in 16S rRNA HaeIII T-RFLP profiles of all six chemostats, including samples from the inoculum (day 0), the start-up period (days 4, 20), and before (days 42, 56, 111), during (days 44, 58, 114) and after (days 47, 61, 117) each perturbation. The legend denotes the size of several important T-RFs and the genus they corresponded to in previous in silico clone library analysis and T-RFLP of isolates (Gentile et al., 2007). 
sequences in the clone library were carefully examined, and restriction enzyme HaeIII was selected to distinguish between the functionally distinct populations.

Replication of community structure during startup. The degree of replication of community structure during start-up can be examined by comparing the first four samples from days 0, 4, 20 and 42. In all six chemostats, community structure was similar to the inoculum in samples from days 4 and 20, but significant differences appeared in the sample taken immediately before the implementation of the first perturbation on day 42 (Figure 4). The inoculum contained terminal restriction fragments 31, 197, 199, 215, 315 and 401 basepairs (bp) in length in significant relative abundances, and these T-RFs were also found in samples from all chemostats on days 4 and 20. By day 42, however, the communities in R1 and R4 shifted to new, unique structures, while the communities in R2, R3, R5 and R6 remained similar to the inoculum. In R1, the relative abundance of the $215 \mathrm{bp}$ T-RF increased on day 42 , while the relative abundances of the 197 and $31 \mathrm{bp}$ T-RFs declined to low levels. This new community structure remained in R1 for the duration of the experiment, with the exception of the sample from day 109, taken shortly after clogging of the feed line. In R4, the community structure shifted on day 42 as a new T-RF $217 \mathrm{bp}$ in size increased in relative abundance, while the relative abundances of the 31 , 197 and $215 \mathrm{bp}$ T-RFs declined. As in R1, the new community structure observed in R4 on day 42 was maintained for the duration of the experiment.

Community dynamics in response to perturbation. To assess community dynamics within each chemostat in response to perturbation, samples taken before (days 42, 56, 111), during (days 44, 48,114 ) and after the perturbations (days 47, 61, 117) were compared. In contrast to the obvious shifts in community structure in two of the chemostats during start-up, the community structure in each chemostat was generally stable throughout the perturbation. Within each chemostat, profiles generally contained the same T-RFs in similar relative abundances throughout the perturbations. An exception was the previously mentioned shift in the community structure in R1 on day 109, presumably due to the clogged feed line. A second exception was the large increase in relative abundance of the 31 bp fragment in R5 on day 111.

Quantitative comparison of community structure (cluster analysis). To quantitatively assess the initial divergence and subsequent stability of community structure observed by visual inspection of T-RFLP histograms, cluster analysis was conducted. Profiles were quantitatively compared using the Bray-Curtis coefficient based on relative abundance data. Cluster analysis was then performed on the

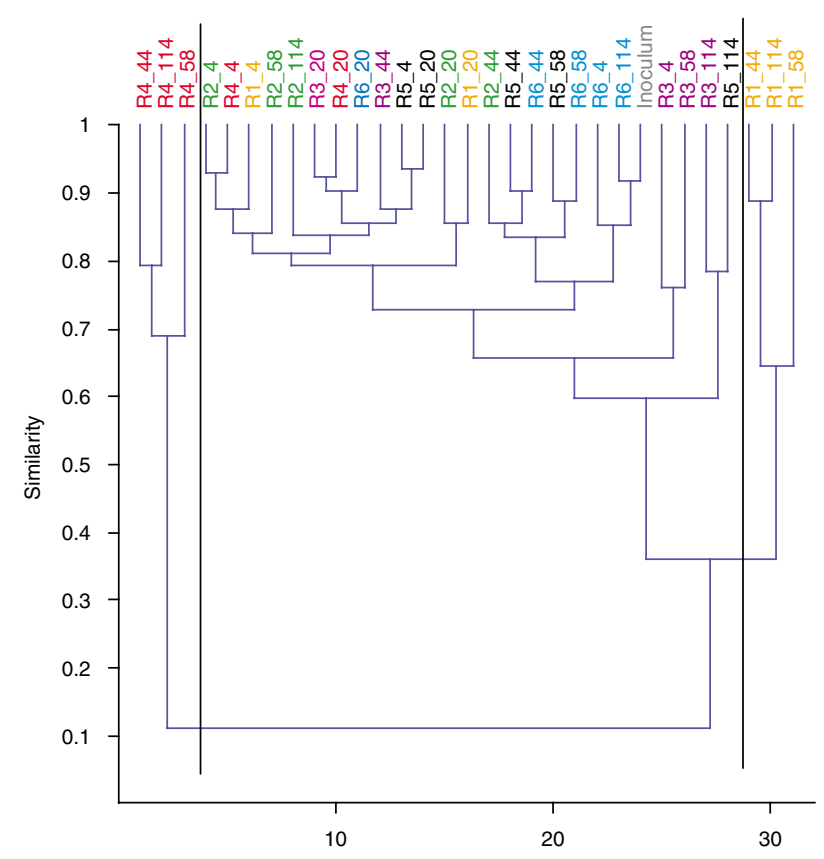

Figure 5 Dendogram representing results of UPGMA clustering determined using a matrix of Bray-Curtis coefficients based on T-RF relative abundance data.

matrix of pair-wise coefficients (Figure 5). The cluster analysis results were consistent with observations from a visual comparison of the histograms. A distinct cluster formed containing the samples from $\mathrm{R} 4$ after day 42 , indicating that the community structure patterns of these samples were the most similar to each other and very different from those of all other samples. The samples from R1 after day 42 also formed a distinct cluster. The samples in this cluster were more similar to each other than to all other samples, although the samples in this cluster were more similar to the samples from R2, R3, R5 and R6 than to the samples from R4. Samples from R2, R3, R5 and R6 and the samples from R1 and R4 before day 42 clustered together, without any apparent patterns among chemostats or over time.

Correspondence of T-RFs with isolates and a previously constructed clone library. Isolates were obtained from the community used as the source of organisms for these studies (Gentile et al., 2007). The isolates were analyzed by T-RFLP to determine the size of their terminal restriction fragments. These determinations were confirmed by in silico digestion of a clone library constructed from the community used to inoculate the chemostats (Gentile et al., 2007). The results are given in the legend of Figure 4.

In the four chemostats that maintained community structures similar to the inoculum (R2, R3, R5 and R6), the community structure was characterized by the presence of the $31,197,199,215,315$ and $401 \mathrm{bp}$ T-RFs. The 215, 315 and $401 \mathrm{bp}$ T-RFs were also present in R1, but generally at greater relative 
Table 2 Functional diversity of isolates

\begin{tabular}{lcll}
\hline Isolate & $T-R F(b p)$ & Closest relative & Intermediates and end products \\
\hline G1 & 215 & Acidovorax sp. LW1 & $\mathrm{NO}_{3}^{-} \rightarrow \mathrm{N}_{2}$ \\
D6 & 217 & Achromobacter xylosoxidans & $\mathrm{NO}_{3}^{-} \rightarrow \mathrm{NO}_{2}^{-}$ \\
M2 & 197 & Delftia acidovorans & $\mathrm{NO}_{3}^{-} \rightarrow \mathrm{NO}_{2}^{-}$ \\
D3 & 31 & Pseudomonas sp. QD03 & $\mathrm{NO}_{3}^{-} \rightarrow \mathrm{NO}_{2}^{-} \rightarrow \mathrm{N}_{2} \mathrm{O} \rightarrow \mathrm{N}_{2}$ \\
\hline
\end{tabular}

The size of the HaeIII T-RF generated and the genus of the closest relative in the RDP are given for each isolate as well as the intermediates and end products detected during batch nitrate reduction assays.

abundances. The previous analysis of clones and isolates revealed that the 197 and 215 bp T-RFs were generated by $16 \mathrm{~S}$ rRNA sequences closely related to the Delftia acidovorans and Acidovorax sp. LW1, respectively, both of which also generated pseudoT-RFs 315 and $401 \mathrm{bp}$ in length (Gentile et al., 2007). Pseudo-T-RFs are fragments that are formed from partially single-stranded amplicons that are cleaved at the second or third occurrence of the restriction site (Egert and Friedrich, 2003).

The $31 \mathrm{bp}$ HaeIII T-RF correlated with several different isolates and genera among the clones and isolates (Gentile et al., 2007). To differentiate among these genera, a second enzyme, Tail, was used to analyze the isolates and community samples from R2, R3, R5 and R6 from samples taken before perturbation on days 42, 56 and 111 (Supplementary Figure S8). In these samples, a $140 \mathrm{bp}$ T-RF was present, and the same T-RF was produced by $\mathrm{T}$ RFLP of the isolate most closely related to Pseudomonas sp. QD3. The Pseudomonas sp. QD3 isolate also produced a $199 \mathrm{bp}$ T-RF when digested with HaeIII. None of the other T-RFs corresponding to those produced by TaiI digests of the other isolates which produced the $31 \mathrm{bp}$ HaeIII T-RF were detected in these chemostat samples.

The TaiI T-RFLP profile from R5 on day 111 was distinct from the other profiles. In that profile, the relative abundance of the $140 \mathrm{bp}$ Pseudomonas-like T-RF was in a lower relative abundance than generally detected in the other samples and two additional, unidentified TaiI fragments 129 and $131 \mathrm{bp}$ in length were present in equal relative abundance $(24 \%)$.

The TaiI digests (Supplementary Figure S8) also revealed the presence of a $519 \mathrm{bp}$ T-RF which corresponded to the $513 \mathrm{bp}$ TaiI T-RF predicted by in silico digest of the clone library sequence most closely related to the propionic acid bacterium Anaerovibrio glycerini. The relative abundance of the $519 \mathrm{bp}$ T-RF increased over time in the lactate fermentation assay, confirming this putative identification. Anerovibrio-like T-RFs were present in profiles from before the second perturbation (day 56) in R2 (although the relative abundance is too low to be seen on the histogram in Supplementary Figure S8) and R6. These two chemostats both produced propionate before and after the second perturbation. Anaerovibrio-like T-RFs were also present in R2, R3, R5 and R6 before the third perturbation (day 111), and propionate was again detected in all chemostats, except R6, before and after the third perturbation. No Anaerovibrio-like T-RF was detected in samples taken before the first perturbation (day 42) when no propionate was produced. The molecular evidence together with the propionate data and fermentation assay results indicate that propionic acid bacteria were present and active, provided an additional electron sink, and generated propionate and acetate as potential additional electron donors for denitrification.

\section{Functional diversity of isolates}

Representative isolates of the Acidovorax-, Delftia-, Achromobacter-, and Pseudomonas-like T-RFs were assayed for reduction of nitrate and production of nitrite, nitrous oxide and dinitrogen gas (Table 2). The electron donors lactate and ethanol were tested in separate assays. The Acidovorax-like isolate reduced nitrate to dinitrogen gas without the accumulation of nitrite or nitrous oxide. The Pseudomonas-like isolate reduced nitrate to dinitrogen gas, but accumulated high concentrations of nitrite and nitrous oxide. The Delftia- and Achromobacter-like isolates reduced nitrate stoichiometrically to nitrite without detectable production of nitrous oxide or dinitrogen gas and were, therefore, classified as nitrate reducers rather than true denitrifiers. Results were the same for all isolates on both lactate and ethanol. In addition, the Acidovorax-like isolate was tested in batch assays with nitrite provided as the electron acceptor rather than nitrate and was able to reduce nitrite directly to nitrogen without the accumulation of nitrous oxide.

Correlation of the Pseudomonas-like T-RF with nitrous oxide resistance

The relative abundance of the T-RF corresponding to the nitrous oxide-accumulating Pseudomonas-like denitrifier was particularly related to the accumulation of nitrous oxide in response to perturbation. When the relative abundance of the Pseudomonaslike TaiI T-RF was high, the accumulation of nitrous oxide as measured by resistance was also high; when the relative abundance of this T-RF fragment 


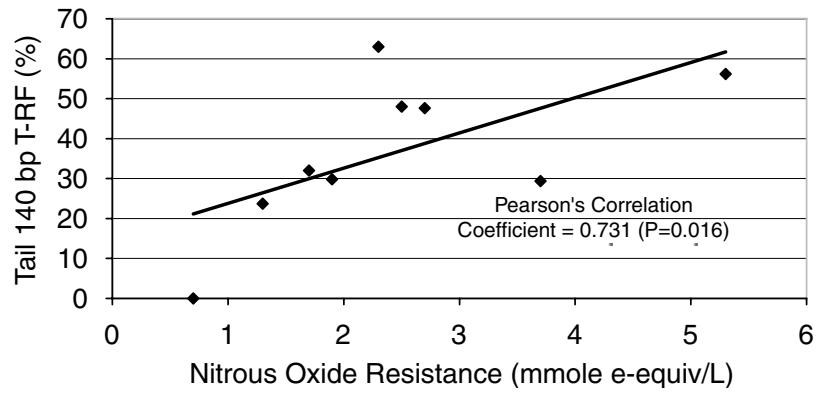

Figure 6 Correlation of nitrous oxide resistance with the relative abundance of the $140 \mathrm{bp}$ TaiI T-RF for chemostats R2, R3, R4, R5 and R6.

was low, the nitrous oxide resistance was low (Figure 6). The Pearson's correlation coefficient was used to determine the strength and significance of the relationship between the Pseudomonas-like TaiI T-RF relative abundance and the nitrous oxide resistance, with values of the coefficient close to one indicating a strong correlation (Bluman, 2001). The relationship was strong and significant with a Pearson's correlation coefficient of $0.731(P=0.016)$.

\section{Discussion}

This study explores the impact of divergence in microbial community structure on denitrification stability. The microbial community structure in two of six replicates diverged significantly from the other four in this study. This degree of replication was lower than that reported in five replicated, denitrifying biofilm reactors in a previous study (McGuinness et al., 2006). In that study, the microbial communities were dynamic, and the differences in community structure between samples were greater than the differences among reactors. In contrast, after the microbial communities diverged in the present study, the differences in community structure between chemostats were greater than the differences observed over time. Differences between the systems in these two studies (biofilm growth versus dispersed growth, different innocula) may account for the different degree of replication. There were also differences in the data analysis, with presence and absence data used in the McGuinness study as opposed to relative abundance data in this study. When cluster analysis of the dataset of the present study was based upon presence absence data rather than relative abundance data (results not shown), R1 was not differentiated from R2, R3, R5 and R6, comparable to the reproducibility of the five reactors in the McGuinness et al.'s (2006) study.

In this study, the microbial communities were not dynamic in response to perturbation. Despite the $60 \%$ increase in the nitrate concentration during each perturbation and the growth that occurred in response to the first perturbation, the communities had high similarity, as measured by the Bray-Curtis coefficients, within each chemostat before, during and after each perturbation. This lack of community dynamics contrasts with the dynamic methanogenic communities observed following a glucose pulse in two separate anaerobic digester experiments (Fernandez et al., 2000; Sundh et al., 2003).

Rather than differences in community dynamics, the differences in extant microbial community structure among chemostats corresponded to the general variations in the observed functional response. In general, three distinct functional responses were observed: (1) high accumulation of nitrous oxide, (2) low accumulation of nitrous oxide and (3) increases in the effluent concentration of nitrate. These responses corresponded to differentiation of the community structure in R1 (increases in effluent nitrate concentrations) and in R4 (low accumulation of nitrous oxide) from the community structures in R2, R3, R5 and R6 (high accumulation of nitrous oxide) as shown by cluster analysis based upon relative abundance of T-RFs.

Functional diversity of isolates provided a potential explanation for the correspondence between community structure and the compound that increased in the effluent in response to perturbation. Nitrate reduction assays of isolates representing the Acidovorax, Delftia, Pseudomonas and Achromobacter-like T-RFs revealed a diversity of nitrate reduction patterns. The Acidovorax-like isolate reduced nitrate to dinitrogen gas without accumulation of nitrite or nitrous oxide. When the Acidovorax-like T-RF dominated T-RFLP profiles, as in R1, the amount of nitrate that was reduced decreased in response to a decrease in the electron donor to electron acceptor ratio (second and third perturbations), but the nitrate that was reduced was completely transformed to dinitrogen gas.

The community structure of the chemostats that accumulated nitrous oxide (R2, R3, R4, R5 and R6) differed from R1, because they contained greater relative abundances of the T-RFs corresponding to the Delftia-like and Achromobacter-like nitrate respirers and the nitrite- and nitrous oxide-accumulating Pseudomonas-like denitrifier. During the second and third perturbations, these chemostats continued to reduce the entire influent nitrate, but the reduction was incomplete and nitrous oxide accumulated. The relationship between the nitrous oxide-accumulating Pseudomonas-like population and the accumulation of nitrous oxide was strong and statistically significant as measured by the Pearson's correlation coefficient. Although the Delftia-like and Achromobacter-like nitrate respirers were present in R2, R3, R5 and R6, nitrite did not accumulate in these chemostats, suggesting that the other populations reduced the nitrite produced by the nitrate respirers. The Acidovorax-like isolate was able to reduce nitrite directly with lactate and ethanol in batch assays (data not shown), so it could have consumed the nitrite produced by nitrate respirers in R2, R3, R5 and R6. The Pseudomonas- 
like isolate was not tested for nitrite reduction specifically, but Pseudomonas-like populations could have also consumed nitrite produced by nitrate respirers in $\mathrm{R} 4$.

Although R5 had similar community structure based on HaeIII digests to the other chemostats that accumulated high concentrations of nitrous oxide, its response to the third perturbation was different from that observed in any other chemostat during any other perturbation, with both nitrate and nitrous oxide accumulating. The community structure of R5 was different from the other chemostats when digested by Tail (data not shown), due to the appearance of unique T-RFs 129 and $131 \mathrm{bp}$ in length. This difference could account for the simultaneous accumulation of nitrate and nitrous oxide. In this case, however, the function of organisms contributing to this unique T-RF could not be assayed, because a representative was not obtained during isolations.

The results of this study suggest that the capabilities and relative abundance of specific populations within denitrifying communities are key determinants of functional stability. Additional research is needed to elucidate factors controlling the relative abundance of these populations.

\section{Acknowledgements}

This research was supported in part by the ERSP, Biological and Environmental Research, US Department of Energy (Grant \#DOEAC05-00OR22725). Margaret Gentile was supported by a fellowship from the US Environmental Protection Agency Science to Achieve Results program. The authors would also like to thank two anonymous reviewers for their thoughtful comments and contributions to this manuscript.

\section{References}

Almeida J, Julio S, Reis M, Carrondo M. (1995). Nitrite inhibition of denitrification by Pseudomonas fluorescens. Biotechnol Bioeng 46: 194-201.

Betlach M, Tiedje J. (1981). Kinetic explanation for accumulation of nitrite, nitric-oxide, and nitrousoxide during bacterial denitrification. Appl Environ Microbiol 42: 1074-1084.

Bluman A. (2001). Elementary Statistics: A Step by Step Approach. McGraw-Hill: New York, NY.

Briones A, Raskin L. (2003). Diversity and dynamics of microbial communities in engineered environments and their implications for process stability. Curr Opin Biotechnol 14: 270-276.

Carlson C, Ingraham J. (1983). Comparison of denitrification by Pseudomonas stutzeri, Pseudomonas aeruginosa and Paracoccus denitrificans. Appl Environ Microbiol 45: 1247-1253.

Curtis T, Head I, Graham D. (2003). Theoretical ecology for engineering biology. Environ Sci Technol 37: $64 \mathrm{~A}-70 \mathrm{~A}$.
Drysdale GD, Kasan HC, Bux F. (2001). Assessment of denitrification by the ordinary heterotrophic organisms in an NDBEPR activated sludge system. Water Sci Technol 43: 147-154.

Dunbar J, Ticknor L, Kuske C. (2000). Assessment of microbial diversity in four southwestern United States soils by $16 \mathrm{~S}$ rRNA gene terminal restriction fragment analysis. Appl Environ Microbiol 66: 2943-2950.

Eaton A, Clesceri L, Greenberg A. (1995). Standard Methods for the Examination of Water and Wastewater. American Public Health Association: Washington, DC.

Egert M, Friedrich MW. (2003). Formation of pseudoterminal restriction fragments, a PCR-related bias affecting terminal restriction fragment length polymorphism analysis of microbial community structure. Appl Environ Microbiol 69: 2555-2562.

Fernandez AS, Hashsham SA, Dollhopf SL, Raskin L, Glagoleva O, Dazzo FB et al. (2000). Flexible community structure correlates with stable community function in methanogenic bioreactor communities perturbed by glucose. Appl Environ Microbiol 66: 4058-4067.

Gentile M, Nyman J, Criddle C. (2007). Correlation of functional instability and community dynamics in denitrifying dispersed growth reactors. Appl Environ Microbiol 73: 680-690.

Gentile M, Yan T, Tiquia SM, Fields M, Nyman J, Zhou J et al. (2006). Stability in a denitrifying fluidized bed reactor. Microbiol Ecol 52: 311-321.

Glass C, Silverstein J. (1998). Denitrification kinetics of high nitrate concentration water: $\mathrm{pH}$ effect on inhibition and nitrite accumulation. Water Res 32: 831-839.

Glass C, Silverstein J, Oh J. (1997). Inhibition of denitrification in activated sludge by nitrite. Water Environ Res 69: 1086-1093.

Grimm V, Schmidt E, Wissel C. (1992). On the application of stability concepts in ecology. Ecol Modell 63: 143-161.

Hammer O, Harper D, Ryan P. (2001). PAST: Paleontological statistics software package for education and data analysis. Palaeontol Electronica 4: 9.

Hashsham S, Fernandez A, Dollhopf S, Dazzo F, Hickey R, Tiedje J et al. (2000). Parallel processing of substrate correlates with greater functional stability in methanogenic bioreactor communities perturbed by glucose. Appl Environ Microbiol 66: 4050-4057.

Hwang C, Wu W-M, Gentry T, Carley J, Carroll S, Schadt C et al. (2005). Changes in bacterial community structure correlate with initial operating conditions of a field-scale denitrifying fluidized bed reactor. Appl Microbiol Biotechnol 15: 1-13.

Kaplan CW, Astaire JC, Sanders ME, Reddy BS, Kitts CL. (2001). 16S ribosomal DNA terminal restriction fragment pattern analysis of bacterial communities in feces of rats fed Lactobacillus acidophilus NCFM. Appl Environ Microbiol 67: 1935-1939.

Lane D. (1991). 16S/23S rRNA Sequencing. In: Stackebrant E, Goodfellow M (ed). Nucleic Acid Techniques in Bacterial Systematics. John Wiley \& Sons: New York, New York, pp 115-175.

Legendre P, Legendre L. (1998). Numerical Ecology. Elsevier Science B.V.: Amsterdam.

Martienssen M, Schops R. (1999). Population dynamics of denitrifying bacteria in a model biocommunity. Water Res 33: 639-646. 
McGuinness LM, Salganik M, Vega L, Pickering KD, Kerkhof LJ. (2006). Replicability of bacterial communities in denitrifying bioreactors as measured by PCR/ T-RFLP analysis. Environ Sci Technol 40: 509-515.

Rittmann BE, Hausner M, Loffler F, Love NG, Muyzer G, Okabe $\mathrm{S}$ et al. (2006). A vista for microbial ecology and environmental biotechnology. Environ Sci Technol 40: 1096-1103.

Rittmann BE, McCarty PL. (2001). Environmental Biotechnology: Principles and Applications. McGraw-Hill: New York, NY.
Sundh I, Carlsson H, Nordberg A, Hansson M, Mathisen B. (2003). Effects of glucose overloading on microbial community structure and biogas production in a laboratory-scale anaerobic digester. Bioresourse Technol 89: 237-243.

US Government Printing Office (2002). National Primary Drinking Water Regulations, CFR title 40. US Government Printing Office: Washington, DC.

Wilhelm E, Battino R, Wilcock RJ. (1977). Low-pressure solubility of gases in liquid water. Chem Rev 77: 219-262.

Supplementary Information accompanies the paper on The ISME Journal website (http://www.nature.com/ismej) 